\title{
Homogeneous cellulose thin films by regeneration of cellulose xanthate: properties and characterization
}

\author{
Michael Weißl · Katrin Niegelhell • David Reishofer • Armin Zankel • \\ Josef Innerlohinger $\cdot$ Stefan Spirk (i)
}

Received: 31 July 2017 / Accepted: 11 November 2017 / Published online: 15 November 2017

(C) The Author(s) 2017. This article is an open access publication

\begin{abstract}
The preparation and characterization of cellulose thin films derived from cellulose xanthate is reported. The films are prepared by depositing alkaline aqueous solutions of cellulose xanthate onto silicon wafers, followed by a spin coating step. Depending on the xanthate concentration used for spin coating, films with 50 and $700 \mathrm{~nm}$ thickness are obtained. The cellulose xanthate is converted to cellulose by exposing the films to $\mathrm{HCl}$ vapors over a period of $20 \mathrm{~min}$. The conversion is monitored by ATR-IR
\end{abstract}

Electronic supplementary material The online version of this article (https://doi.org/10.1007/s10570-017-1576-3) contains supplementary material, which is available to authorized users.

M. Weiß1

Institute for Chemistry and Technology of Materials, Graz University of Technology, Stremayrgasse 9, 8020 Graz, Austria

M. Weißl - K. Niegelhell · D. Reishofer · S. Spirk ( $₫)$ Institute for Paper, Pulp and Fibre Technology, Graz University of Technology, Inffeldgasse 23A, 8010 Graz, Austria

e-mail: stefan.spirk@tugraz.at

A. Zankel

Institute for Electron Microscopy and Nanoanalysis, NAWI Graz, Graz University of Technology and Centre for Electron Microscopy, Steyrergasse 17, 8010 Graz, Austria

J. Innerlohinger

Lenzing AG, Werkstrasse 2, 4860 Lenzing, Austria spectroscopy, which allows for tracking the rupture of $\mathrm{C}-\mathrm{S}$ and $\mathrm{C}=\mathrm{S}$ bonds during the regeneration process. The conversion is accompanied by a reduction of the film thickness of ca $40 \%$ due to the removal of the bulky xanthate group. The films feature a homogenous, but porous morphology as shown by atomic force microscopy. Further, the films were investigated towards their interaction with Bovine Serum Albumin (BSA) and fibrinogen by means of multi-parameter surface plasmon resonance spectroscopy. Similar as other cellulose thin films BSA adsorption is low while fibrinogen adsorbs to some extent at physiological $\mathrm{pH}$ (7.4).

Keywords Cellulose thin films - Xanthate - Vapor phase hydrolysis · Protein adsorption

\section{Introduction}

In recent years, cellulose thin films have attracted significant interest in both basic and applied research since they provide a confined two dimensional environment with defined morphology and chemistry (Kontturi et al. 2003, 2006, 2013). Therefore, they have been proposed as supports for biosensors, as matrix for catalysis as well as material for optoelectronic devices such as transistors and solar cells (Blomstedt et al. 2007; Filpponen et al. 2012; 
Niegelhell et al. 2016; Orelma et al. 2011, 2012; Reishofer et al. 2017; Taajamaa et al. 2013; Wolfberger et al. 2015). Further, these films have been employed as models to investigate and to better understand interactions of water with cellulose, particularly in the context of cell wall structure and their relation to industrially applied drying processes (Ehmann et al. 2015; Niinivaara et al. 2015, 2016).

The strategies to prepare such films are based on three main approaches which comprise either (1) the use of cellulose suspensions, (2) the dissolution of cellulose or (3) the employment of cellulose derivatives which are converted back to cellulose after the film forming process (Kontturi et al. 2006). The advantage of using suspensions is to avoid the use of organic solvents but the obtained films are not completely flat due to the (nano)fibrous or particulate nature of the cellulosic starting materials. In contrast, the preparation of cellulose thin films derived from dissolved cellulose requires tedious dissolution procedures (e.g. DMA/LiCl or ionic liquids) (Kargl et al. 2015). Additionally, the solvent (and/or salt) needs to be removed from the films, which necessitates extensive washing procedures of the films. An elegant method to prepare cellulose thin films overcoming these problems has been introduced by Klemm in 1993 and further developed by Kontturi in the beginning of the century. (Kontturi et al. 2003; Schaub et al. 1993) The method employs an acid labile organosoluble cellulose derivative, trimethylsilyl cellulose (TMSC), which is converted to cellulose after processing by simple exposure to $\mathrm{HCl}$ vapors. Since the whole process runs via gas phase reaction and since only volatile side products are formed, washing steps are not necessary. In addition, the solubility of this cellulose derivative can be tuned by variation of the $\mathrm{DS}_{\mathrm{TMS}}$ and therefore allows easy manufacturing, e.g. by spin coating, the most common thin film formation technique. The films obtained by this process are smooth and featureless with RMS roughnesses of down to $1.5 \mathrm{~nm}$ as determined by atomic force microscopy. However, although TMSC is a commercial cellulose derivative, whose production is in principle scalable, it is a rather expensive material. Although eco-solvents such as ethyl acetate have been proposed as solvents for TMSC, the use of an aqueous cellulose solution for film formation would be desirable (Wolfberger et al. 2014, 2015).
In this context, a widely used, water soluble cellulose derivative, which can be easily converted back to cellulose, is cellulose xanthate (CX). CX has been first prepared already in the end of the nineteenth century and was since then used as a soluble cellulose derivative for the production of regenerated fibers and films. In a typical fiber/film producing process, the xanthates are regenerated by immersion in an acidic bath which in addition contains some additives to improve fiber/film properties. Nowadays, the market for viscose based products is steadily increasing by ca $10 \%$ year whereas specialities become more and more attractive to manufactures (Götze 1951; Hämmerle 2011).

For all these reasons, we became interested whether cellulose xanthate can be employed for the formation of thin cellulose films having film thicknesses below $100 \mathrm{~nm}$. Cellulose thin films from TMSC have shown potential for some applications but the use of CX as starting material may lead to new materials with interesting properties while being biobased and scalable to large quantities. The resulting films could then either be converted by simple immersion in an acidic bath to regenerate the cellulose or to expose them to an acidic atmosphere (e.g. $\mathrm{HCl}$ ) similar to TMSC films. In the following, we report our approach to prepare such films starting from different concentrations of cellulose xanthate in aqueous alkaline solutions and their influence on film properties.

\section{Experimental}

\section{Materials}

A cellulose xanthate (CX) stock solution (10 wt $\%$, gamma: 52, $\mathrm{NaOH}: 6 \%$, degree of polymerization: 550) was provided by Lenzing AG (Lenzing, Austria) and used without any further treatment. CX solutions with $0.75,1.0,1.5,2.0,2.5,3.0$ and $4.0 \mathrm{wt} \%$ were prepared by adding de-ionized water from an Elga PURELAB Prima (Bucks, United Kingdom) water treatment system to the stock solutions. Afterwards, the solutions were vigorously mixed using a vortex shaker over a period of $30 \mathrm{~s}$, followed by a filtration step. Sulfuric acid (95 wt\%) and hydrochloric acid (37 wt $\%$ ) were purchased from VWR Chemicals and hydrogen peroxide $(30 \mathrm{wt} \%)$ from Sigma-Aldrich. Silicon wafers, glass slides (Roth), Au-coated glass 
slides as substrate (SPR102-AU), Filter Chromafil Xtra PVDF-45/25 $0.45 \mu \mathrm{m}$ were used as obtained. BSA and fibrinogen were purchased from Sigma, Aldrich.

Cellulose thin film preparation

As substrates for the cellulose films, single side polished silicon wafers from Siegert Wafers (Aachen, Germany, wafer thickness: $675 \pm 25 \mu \mathrm{m}$, $1 \mathrm{~cm} \times 1 \mathrm{~cm}$ ) and gold coated glass slides from BioNavis (Tampere, Finland, gold layer thickness: $50 \mathrm{~nm}, 1 \mathrm{~cm} \times 2 \mathrm{~cm}$ ) were used. The slides were cleaned by dipping them into piranha acid $\left[\mathrm{H}_{2} \mathrm{SO}_{4}\right.$ :$\left.\mathrm{H}_{2} \mathrm{O}_{2}=3: 1(\mathrm{v} / \mathrm{v})\right]$ for $30 \mathrm{~min}$ (10 min for gold slides) and intensely washed with MilliQ water afterwards.

For spin coating, $80 \mu \mathrm{l}$ of viscose solution (per square centimeter substrate) were deposited onto the surfaces and subjected to spin coating $\left(\mathrm{a}=2500 \mathrm{rpm} \mathrm{s}^{-1}, \mathrm{v}=4000 \mathrm{rpm}, \mathrm{t}=60 \mathrm{~s}\right)$. Afterwards, the thin films were stored at room temperature overnight, followed by regeneration of the deposited $\mathrm{CX}$ layers in vaporous $\mathrm{HCl}$ atmosphere (created from concentrated hydrochloric acid). During the regeneration procedure, the $\mathrm{HCl}$ was deposited into a petri dish, and the substrates were positioned above the liquid $\mathrm{HCl}$ phase in another petri dish. A third petri dish was used as a lid to close the system. After $20 \mathrm{~min}$ exposure to the gaseous $\mathrm{HCl}$ atmosphere, regeneration of the cellulose xanthates to cellulose is accomplished as proven by ATR-IR spectroscopy. Afterwards, the films were rinsed twice with water $(3 \mathrm{ml})$ followed by drying in a stream of dry nitrogen.

\section{Optical microscopy}

Light microscopy investigations were carried out on an Olympus BX60 fitted with an Olympus E-520 camera. Prior to investigating the samples, carrier substrates were fixed on a glass layer.

\section{Profilometry}

The layer thickness was determined with a Bruker DekTak XT surface profiler. The scan length was set to $1000 \mu \mathrm{m}$ over the time duration of $3 \mathrm{~s}$ with the hills and valleys scanning profile. The diamond stylus had a radius of $12.5 \mu \mathrm{m}$ and the employed force was $3 \mathrm{mg}$. The measured profile was then used to determine the thickness. Each layer thickness has been determined by averaging 6 measurements on three different slides.

Attenuated total reflection: infrared spectroscopy

The infrared spectra were recorded with an ALPHA FT-IR spectrometer (Bruker; Billerica, MA, U.S.A.). For the measurement, an attenuated total reflection (ATR) attachment was used with 64 scans at a resolution of $4 \mathrm{~cm}^{-1}$ and a scan range between 4000 and $400 \mathrm{~cm}^{-1}$. The samples were prepared on $\mathrm{Au}-$ coated glass slides (SPR102-AU). The data were analyzed with OPUS 4.0 software.

Atomic force microscopy

The atomic force microscopy (AFM) images were recorded in tapping mode with a Veeco Multimode Quadrax MM AFM (Bruker; Billerica, MA, USA). For the measurements silicon cantilevers (NCH-VS1-W from NanoWorld AG, Neuchatel, Switzerland; Coating: none) with a resonance frequency of $297 \mathrm{kHz}$ were used. All measurements were performed under ambient atmosphere and at room temperature. The image processing and the calculation of the root mean square roughness (calculated from $2 \mu \mathrm{m} \times 2 \mu \mathrm{m}$ and $10 \mu \mathrm{m} \times 10 \mu \mathrm{m}$ images) were done with the Nanoscope software (V7.30r1sr3; Veeco).

Contact angle and surface free energy determination

For the calculation of the surface free energy (SFE) Milli-Q water $\left(\geq 18 \mathrm{M} \Omega \mathrm{cm}^{-1}\right)$ and diiodomethane were employed as test liquids. The drop shape analysis was done in the sessile drop modus at $25^{\circ} \mathrm{C}$ with a DSA100 system (Krüss GmbH, Hamburg, Germany) equipped with a T1E CCD video camera ( $25 \mathrm{fps})$. The dispense rate of the $3 \mu \mathrm{l}$ droplets was adjusted to $166 \mu \mathrm{l} / \mathrm{min}$ and the time before the image was captured was set to $2 \mathrm{~s}$. Each sample was measured at least three times. The contact angle (CA) calculations (software: DSA1 v 1.90) were performed with the Young-Laplace equation and the surface free energy calculation with the Owens-Wendt-Rabel and Kaelble method (Owens and Wendt 1969). 
Scanning electron microscopy: energy-dispersive

$\mathrm{X}$-ray spectroscopy

An ESEM Quanta 600 FEG (FEI, Eindhoven, NL) scanning electron microscope was utilized to examine the surface structure during different steps of film preparation. To gain electrical conductivity a $15 \mathrm{~nm}$ thick carbon layer was vaporized on the film surface before. Images were recorded in the high vacuum mode either with secondary electrons (ETD EverhartThornley detector, giving topographic contrast) or with backscattered electrons (SSD: Solid State Detector, delivering compositional contrast).

Multi parameter surface plasmon resonance spectroscopy

MP-SPR spectroscopy was accomplished with a SPR Navi 200 from Bionavis Ltd., Tampere, Finland, equipped with two different lasers (670 and $785 \mathrm{~nm}$, respectively) in both measurement channels, using gold-coated glass slides as substrate (gold layer $50 \mathrm{~nm}$ ). All measurements were performed using a full angular scan $\left(39^{\circ}-78^{\circ}\right.$, scan speed: $\left.8^{\circ} \mathrm{s}^{-1}\right)$. Protein adsorption was investigated with Bovine Serum Albumin (BSA) $\left(1 \mathrm{mg} \mathrm{ml}^{-1}\right)$ and fibrinogen (FIB) $\left(1 \mathrm{mg} \mathrm{ml}^{-1}\right)$ both in a $100 \mathrm{mM} \mathrm{NaCl}$ solution containing $10 \mathrm{mM}$ PBS at $\mathrm{pH}$ 7.4. Flow was adjusted to $50 \mu \mathrm{min}^{-1}$ for $5 \mathrm{~min}$ at $25^{\circ} \mathrm{C}$. Each measurement was repeated 3 times at least. BioNavis Dataviewer software was used for processing all two wavelength SPR experiments (Scheme 1).

\section{Results and discussion}

In a first step, the film formation properties of CX solutions by spin coating were investigated as a function of the CX concentration. It turned out that the CX concentration must be in a range between 0.75 and $4.0 \mathrm{wt} \%$ to obtain homogenous films on the different substrates (i.e. Si-wafer, glass slides, gold coated glass slides). Below concentrations of $0.75 \mathrm{wt} \% \mathrm{CX}$ incompletely covered films were obtained, whereas above $4.0 \mathrm{wt} \% \mathrm{CX}$ fully covered but inhomogeneous films having a wide range of defects were observed (data not shown). After deposition by spin coating, the solid CX films were regenerated using $\mathrm{HCl}$. When the films were immersed in aqueous $3 \mathrm{M} \mathrm{HCl}$, the films peeled off the substrate; therefore this method was not investigated in further detail. In contrast, the exposure to $\mathrm{HCl}$ vapors created from concentrated hydrochloric acid led to the regeneration of the CX to cellulose. The regeneration of the $\mathrm{CX}$ can be observed by naked eye, particularly when glass slides were employed as substrates. On these films, the yellow CX film steadily decolorizes with time concomitant with the formation of a white particle like coverage on the surface. This white material corresponds to the formation of salt crystals composed of $\mathrm{NaCl}$ (obtained as side product by reaction of the sodium xanthate and $\mathrm{HCl}$ ) and can be easily removed by rinsing the films with water after regeneration (see AFM section). As expected, the higher the concentration of the CX solution used for film preparation was, the more pronounced the formation of this residue was.

The layer thickness of the CX films gradually increased with increasing $\mathrm{CX}$ concentration from $31 \pm 3(0.75 \mathrm{wt} \%)$ to $688 \pm 10 \mathrm{~nm}(4.0 \mathrm{wt} \%)$. One would expect that the films significantly shrink during regeneration since the xanthate group is rather bulky and hydrogen bond formation would lead additionally to densification of the films as known for related cases involving other cellulose derivatives such as TMSC (Kontturi et al. 2011; Mohan et al. 2012). However, directly after exposure of the films to $\mathrm{HCl}$ vapors, the opposite phenomenon was observed. Some films showed an increase in film thickness or did not change significantly which relates to the formation of $\mathrm{NaCl}$, which certainly does not only form on the surface but also in the interior of the film. After removal of $\mathrm{NaCl}$ from the films by rinsing with water, the film thickness reduced significantly. Finally, pure cellulose films with film thicknesses between $21 \pm 2$ and $413 \pm 11 \mathrm{~nm}$ were manufactured. It is of interest that the film with the smallest layer thickness showed just $23 \%$ of shrinking whereas for all the other films shrinkage was between 40 and 44\% (Fig. 1). Similar observations have been made when studying the film thickness reduction during regeneration of TMSC; obviously the substrate limits the shrinking and densification of the films to some extent (Ehmann et al. 2015). Afterwards, the films were subjected to a drying procedure at $105{ }^{\circ} \mathrm{C}$ over a period of $1 \mathrm{~h}$. The films showed a slight shrinkage whereas here the thinnest films were affected to a larger extent $(17 \%$ layer thickness decrease) than the thicker ones (few 


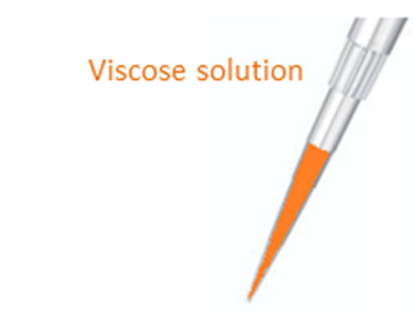

Si-, Au- or glass- wafer

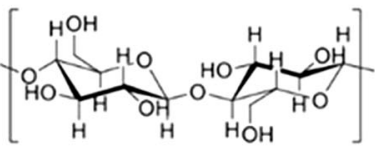

Cellulose layer

$\mathrm{Si}-, \mathrm{Au}$ - or glass- wafer

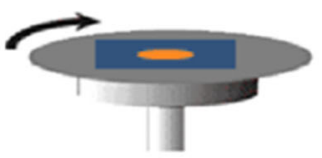

spin-coating

$\mathrm{v}=4000 \mathrm{rpm}$

$\mathrm{a}=2400 \mathrm{rpm} / \mathrm{s}$

$\mathrm{t}=60 \mathrm{~s}$

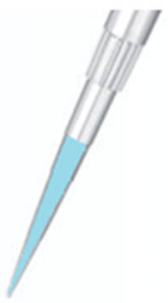

rinsing

$2 \times 3 \mathrm{ml}$ DI water dried in $\mathrm{N}_{2}$ flow

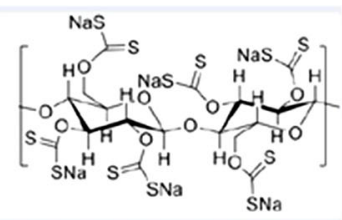

Viscose layer

\section{Si-, Au- or glass- wafer}



Cellulose layer covered with salt

Si-, Au- or glass- wafer

Scheme 1 Cellulose thin film production based on aqueous cellulose xanthate ('Viscose') solutions



Fig. 1 Film thickness changes [\%] in dependence of process parameters

percent decrease). An overview on the layer thickness data is provided in Table 1.

A commonly used method to monitor chemical reactions of cellulose derivatives is IR spectroscopy. A complication in the IR spectroscopic analysis of the CX films arises from the tendency of CX to decompose at ambient conditions. In the case of CX thin films, the IR spectra indicated that significant amounts of CX decomposition products had been formed after spin coating. The decomposition products can be identified as $\mathrm{CS}_{2}\left(v_{\mathrm{C}=\mathrm{S}}\right.$ at $\left.1520 \mathrm{~cm}^{-1}\right)$, sodium sulfide $\left(1420,920 \mathrm{~cm}^{-1}\right)$ and sodium trithiocarbonate (1670, 1427, 925 and $\left.885 \mathrm{~cm}^{-1}\right)$ and, in traces, $\mathrm{H}_{2} \mathrm{~S}\left(v_{\mathrm{S}-\mathrm{H}}\right.$ at $2630 \mathrm{~cm}^{-1}$, Fig. S7, Supporting Information). The remaining bands at 1452 and $1382 \mathrm{~cm}^{-1}$ as well as a weak band at $2725 \mathrm{~cm}^{-1}$ can be assigned to $\mathrm{NaOH}$, which is present in the films stemming from the dissolution of CX (Andrews et al. 1960; Dautzenberg and Philipp 1970; Ogura and Sobue 1968). Since $\mathrm{NaOH}$ is highly hygroscopic, the water peak at $1640 \mathrm{~cm}^{-1}$ is pronounced as well. The $\mathrm{C}-\mathrm{S}$ and $\mathrm{C}=\mathrm{S}$ vibrations for the $\mathrm{CX}$ have been reported in the range between 1050 and $1250 \mathrm{~cm}^{-1}$ and interfere with the decomposition products as well as with vibrations at the pyranose ring, which also show absorption bands 
Table 1 Comparison of the layer thickness $d$ [nm] of the films depending on initial CX concentration by stylus force profilometry

\begin{tabular}{lcccc}
\hline & \multicolumn{1}{c}{$\mathrm{CX}$} & After $20 \mathrm{~min} \mathrm{HCl}$ & Rinsed & Dried $105^{\circ} \mathrm{C}$ \\
\hline $0.75 \mathrm{wt} \%$ & $31 \pm 3$ & $31 \pm 3$ & $24 \pm 2$ & $20 \pm 2$ \\
$1.0 \mathrm{wt} \%$ & $51 \pm 3$ & $58 \pm 2$ & $30 \pm 3$ & $29 \pm 1$ \\
$1.5 \mathrm{wt} \%$ & $103 \pm 2$ & $115 \pm 3$ & $58 \pm 1$ & $59 \pm 1$ \\
$2.0 \mathrm{wt} \%$ & $167 \pm 2$ & $205 \pm 6$ & $96 \pm 3$ & $93 \pm 2$ \\
$2.5 \mathrm{wt} \%$ & $243 \pm 5$ & $309 \pm 6$ & $138 \pm 3$ & $136 \pm 2$ \\
$3.0 \mathrm{wt} \%$ & $401 \pm 4$ & $463 \pm 7$ & $230 \pm 3$ & $229 \pm 2$ \\
$4.0 \mathrm{wt} \%$ & $688 \pm 10$ & $680 \pm 8$ & $413 \pm 11$ & $407 \pm 10$ \\
\hline
\end{tabular}

in this range. Therefore, an unambiguous assignment is not possible (Fig. 2).

During ongoing regeneration, all bands related to $\mathrm{C}=\mathrm{S}$ and $\mathrm{C}-\mathrm{S}$ vibrations as well as the $\mathrm{NaOH}$ disappear and a cellulose II like spectrum is obtained. It seems that the $\mathrm{HCl}$ treatment leads to partial oxidation of the film surface since a weak band at $1762 \mathrm{~cm}^{-1}$ characteristic for $\mathrm{C}=\mathrm{O}$ vibrations in $\mathrm{COOH}$ of oxidized cellulose is observed. Washing the films with water removes the water soluble oxidized cellulose fragments and pure cellulose II films are obtained. This is featured by broad bands from 3600 to $3100 \mathrm{~cm}^{-1}\left(\mathrm{v}_{\mathrm{OH}}\right)$ and from 3000 to $2850 \mathrm{~cm}^{-1}$ (C-H stretching vibrations), a series of small weak bands in the region of $1430-1150 \mathrm{~cm}^{-1}$ (C-O-H bending at $1430 \mathrm{~cm}^{-1}, \mathrm{C}-\mathrm{H}$ deformation at $1372 \mathrm{~cm}^{-1}, \mathrm{OH}$ in plane deformation at 1330 and at $1200 \mathrm{~cm}^{-1}$ ), a strong and overlapping bands from

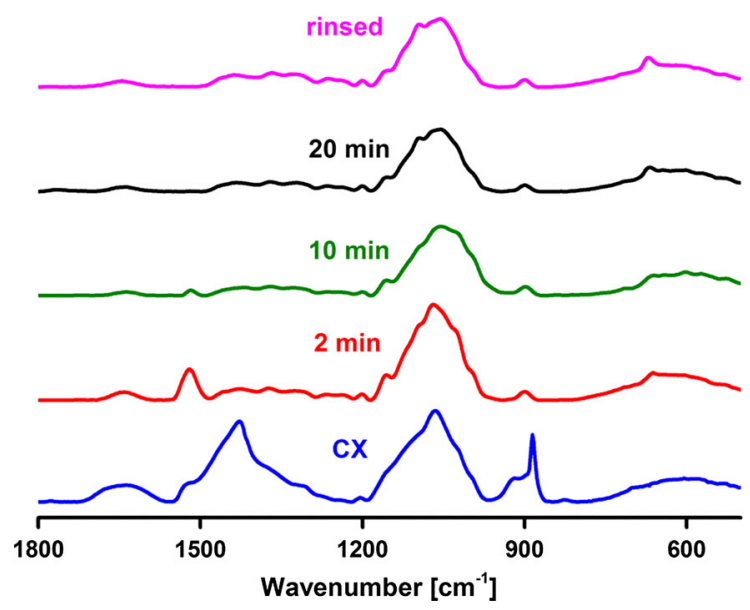

Fig. 2 Smoothed ATR-IR spectra of the $600-2000 \mathrm{~cm}^{-1}$ region of cellulose xanthate films (prepared from a $3 \mathrm{wt} \%$ solution of $\mathrm{CX}$ ) during the exposure to $\mathrm{HCl}$ vapors. The original spectra for the individual exposure times showing the full range can be found in the Supporting Information (Figs. S7-S10)
1160 to $950 \mathrm{~cm}^{-1}$ (asym. C-O-C vibration at $1155 \mathrm{~cm}^{-1}$, sym. C-O vibration at $1060 \mathrm{~cm}^{-1}$ and $\mathrm{C}-\mathrm{O}$ stretching at $1035 \mathrm{~cm}^{-1}$ ) and a small band at $899 \mathrm{~cm}^{-1}$ (C-O-C valence vibration) (Široký et al. 2010). Additionally, the spectra of the regenerated CX films show a band at $1640 \mathrm{~cm}^{-1}$ indicating adsorbed water.

When the CX thin films are stored over a period of 14 days, hydrolysis reactions take place. The intensity of the IR bands at $885,920,1427$ and $1670 \mathrm{~cm}^{-1}$ (corresponding to the sodium trithiocarbonate) decrease, while the intensity of the bands corresponding to the major decomposition products of sodium sulfide and trithiocarbonate, namely sodium carbonate and sodium hydroxide become more intense (1770, 1458, $1378 \mathrm{~cm}^{-1}: \mathrm{Na}_{2} \mathrm{CO}_{3}, 1452,1382: \mathrm{NaOH}$, Fig. S11, Supporting Information) (Ingram and Toms 1957). In addition, the CX partially hydrolyzes as well since the intensity of the bands in the $1000-1250 \mathrm{~cm}^{-1}$ changed as well.

The morphology of the films shows a rather homogeneous surface structure, which is altered by the concentration used for film preparation. In general, an increase of the concentration of CX solutions used for the preparation of the films leads to surfaces with higher RMS roughness $\left(\mathrm{R}_{\mathrm{q}}\right)$ values. Figures 3 $\left(10 \times 10 \mu \mathrm{m}^{2}\right)$ and $4\left(2 \times 2 \mu \mathrm{m}^{2}\right)$ depict two different types of films, one prepared from $2.5 \mathrm{wt} \%$ (Figs. 3a-d, 4a-d) and the other from $1.5 \mathrm{wt} \%$ (Figs. 3e-h, 4e-h) CX solutions. It can be clearly seen that the surfaces feature much higher $\mathrm{R}_{\mathrm{q}}$ values for the $2.5 \mathrm{wt} \%$ films $(6.9 \mathrm{~nm})$ than for the $1.5 \mathrm{wt} \%$ ones $(3.0 \mathrm{~nm})$. The exposure of the films to $\mathrm{HCl}$ vapors leads to a significant increase in roughness to 24 and $28 \mathrm{~nm}$, respectively. However, this increase in roughness is not related to rough cellulose surfaces but to the formation of $\mathrm{NaCl}$ particles on the surfaces. As already indicated for the profilometry results, more particles 

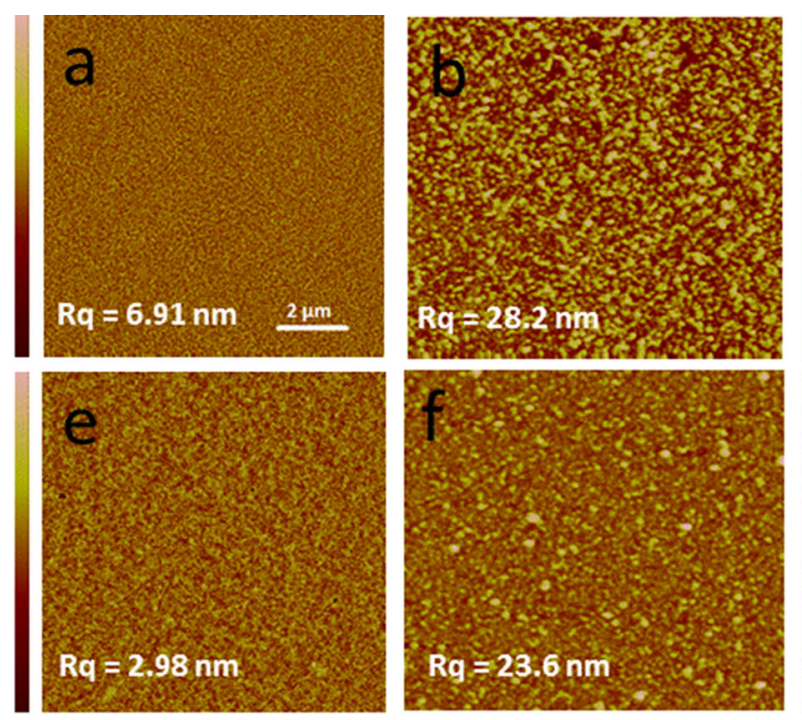

Fig. 3 AFM images $\left(10 \times 10 \mu \mathrm{m}^{2}\right)$ and corresponding RMS roughness of different steps in cellulose thin film processing with a $2.5 \mathrm{wt} \%$ (upper row) and a $1.5 \mathrm{wt} \%$ (lower row) CX solution. The images show the films directly after spin coating
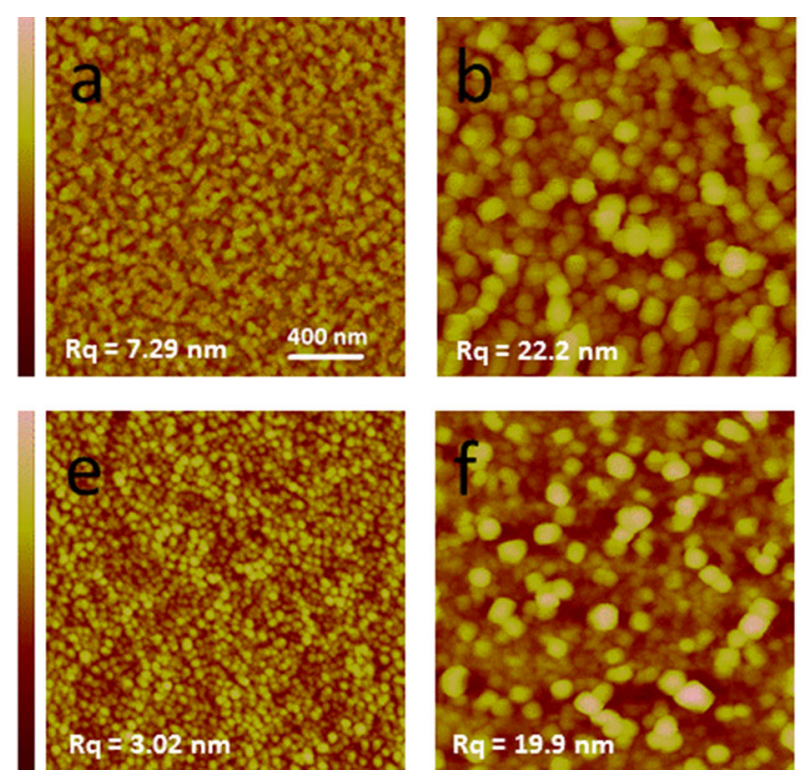

Fig. 4 AFM images $\left(2 \times 2 \mu \mathrm{m}^{2}\right)$ and corresponding RMS roughness of different steps in cellulose thin film processing with a $2.5 \mathrm{wt} \%$ (upper row) and a $1.5 \mathrm{wt} \%$ (lower row) CX solution. The images show the films directly after spin coating

are present on surfaces with increasing CX concentration in solutions prepared for film manufacturing and indeed this can also be observed in the AFM images. When the particles are removed by simply rinsing them with water, $\mathrm{R}_{\mathrm{q}}$ values are reduced to their


(a, e), after 20 min lasting exposure to $\mathrm{HCl}$ atmosphere (b, f), after rinsing with de-ionized water $(\mathbf{c}, \mathbf{g})$ and after drying for $1 \mathrm{~h}$ at $105{ }^{\circ} \mathrm{C}(\mathbf{d}, \mathbf{h})$. Z-scale is $100 / 200 / 50 / 50 \mathrm{~nm}$ for $(\mathbf{a}-\mathbf{d})$ and $30 / 300 / 30 / 50 \mathrm{~nm}$ for $(\mathbf{e}-\mathbf{h})$


(a, e), after $20 \mathrm{~min}$ lasting exposure to $\mathrm{HCl}$ atmosphere (b, f), after rinsing with de-ionized water $(\mathbf{c}, \mathbf{g})$ and after drying for $1 \mathrm{~h}$ at $105{ }^{\circ} \mathrm{C}(\mathbf{d}, \mathbf{h})$. Z-scale is $100 / 200 / 50 / 50 \mathrm{~nm}$ for $(\mathbf{a}-\mathbf{d})$ and $30 / 150 / 100 / 50 \mathrm{~nm}$ for $(\mathbf{e}-\mathbf{h})$

initial values ( 6.8 and $5.1 \mathrm{~nm}$ ), a phenomenon which has been observed for cellulose thin films derived from TMSC as well. The films exhibit homogeneous surface morphology and a subsequent drying step slightly alters the structure, thereby further reducing 
the roughness values. Compared to cellophane, the macroscopic congener, the films do not exhibit a preferred orientation (see Fig. S6 for an AFM image of a cellophane film). This orientation is induced by the drawing of the films in machine direction. As a consequence, the cellophane films show different mechanical properties in machine and cross direction as well as a different hydroexpansion behavior in both directions.

To validate the chemical reactions and the changes in surface morphology appearing in the different steps of cellulose thin film processing, SEM-EDX measurements were performed. The SEM images reveal flower like structures on the surface of CX films directly after the spin coating step (Fig. 5a), which probably originate from sodium hydroxide. These structures are visible in the AFM images as well but since a smaller area was chosen, they could not be identified as separate phase. Further, the growth of crystallites during CX regeneration (Fig. 5b) is visible, which disappear after rinsing with water (Fig. 5c). EDX spectra clearly show that the crystals in Fig. 5b consist of sodium chloride. For the crystals present on the surface of untreated CX films, EDX spectra (Fig. S3-S5, Supporting Information) show a small sulfur peak in addition to the common sodium and chloride peaks. The additional sulfur peak and the different crystalline structure indicate the presence of two different crystals (sodium hydroxide and probably sodium sulfide).

An important parameter for the investigation of the surface properties of cellulose thin films is wettability. However, the determination of water contact angles on CX films could not be performed since the films were partially dissolved by water thereby giving no meaningful results while with $\mathrm{CH}_{2} \mathrm{I}_{2}$ contact angles ranging from $38^{\circ}$ to $60^{\circ}$ were obtained. After regeneration, the presence of $\mathrm{NaCl}$ particles on the surfaces prevented the measurement of the contact angles for both liquids. After rinsing the films with water, static water contact angles between $27^{\circ}$ and $38^{\circ}$ were determined. The drying of the films did not change the wettability with both liquids significantly. In general, these cellulose surfaces are a bit more hydrophobic than those prepared from TMSC where usually static water contact angles between $24^{\circ}$ and $33^{\circ}$ have been reported.

Based on this data, the surface free energies (SFE) of the surfaces were determined according to the Owens-Wendt-Rabel and Kaelble method (Kaelble 1970; Owens and Wendt 1969; Rabel 1971). This method exploits the wettability behavior of two different liquids in order to calculate the total surface free energy as well as the dispersive and polar components. In this paper, water and diiodomethane were chosen as test liquids. Figure 6 illustrates that the surface free energy decreases significantly after rinsing the films with de-ionized water. However, the following heat treatment did not have any substantial impact on the surface free energy. Taking a closer look at the decrease in SFE after the washing step reveals that the polar part of SFE energy stays constant over all process steps and only the disperse part of SFE is slightly changing (Table 2).

SPR spectroscopy is one of the methods of choice to investigate protein adsorption on thin films allowing for the evaluation of the dry adsorbed mass (adsorbed mass without coupled water) as well as the adsorption
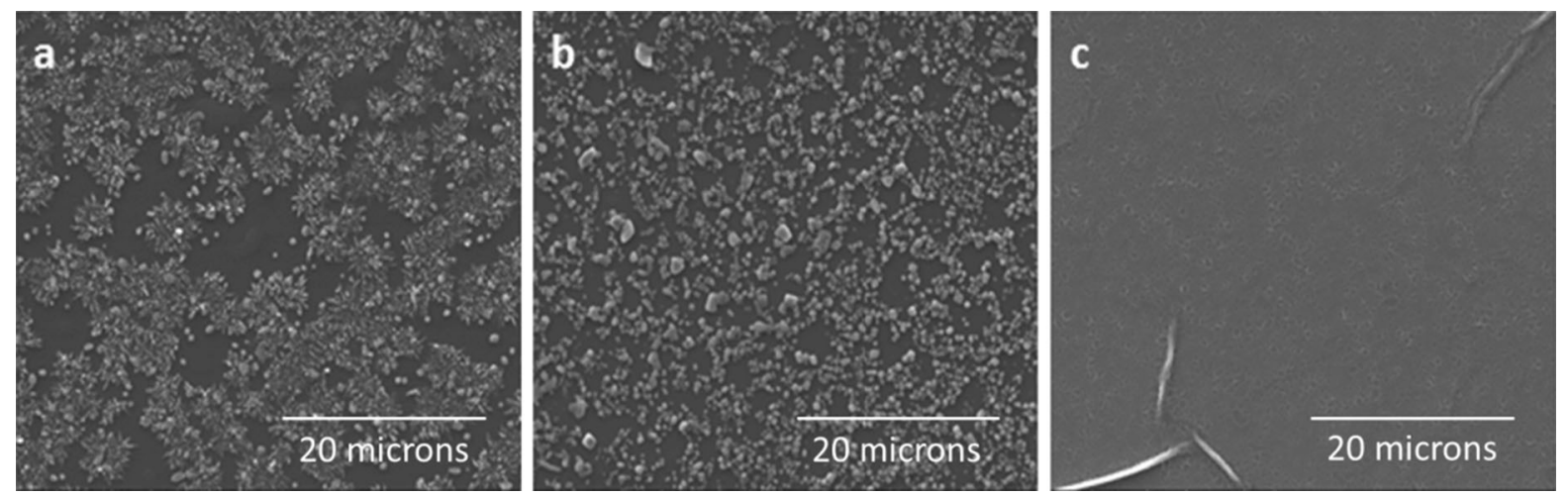

Fig. 5 SEM images displaying the film surface after a spin coating of $2.5 \mathrm{wt} \% \mathrm{CX}$ solution, b regeneration of $\mathrm{CX}$ in $\mathrm{HCl}$ vapor and c after rinsing the film with water 


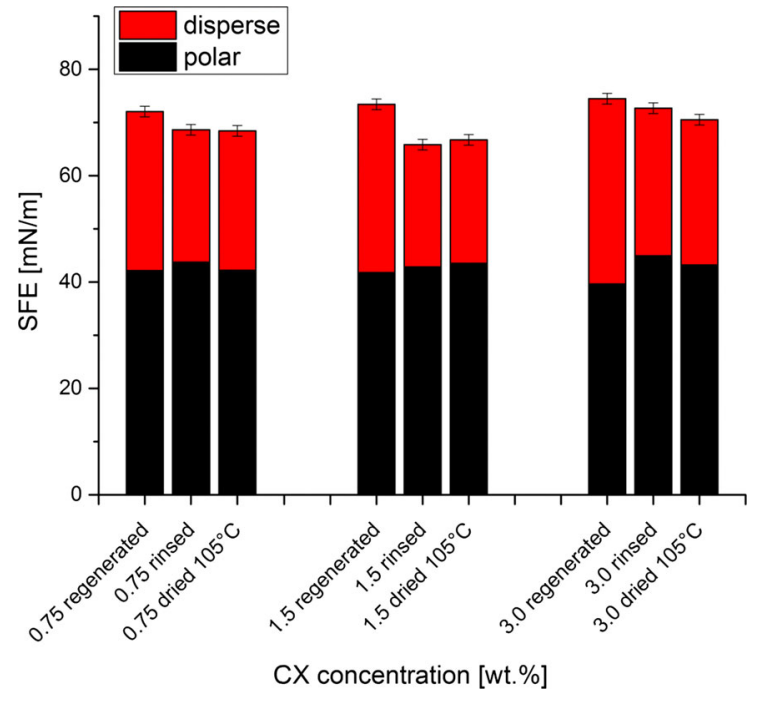

Fig. 6 Surface free energy of cellulose layers prepared from different concentrations, determined directly after film regeneration, rinsing and heat treatment

kinetics. Protein adsorption was tested using bovine serum albumin (BSA), a widely accepted marker for nonspecific protein interaction, and fibrinogen (FIB), a serum protein which plays an important role in the blood coagulation cascade (Pallister and Watson 2010). Since the herein investigated cellulose thin films are potential materials for the usage in life science applications, SPR experiments were accomplished at a $\mathrm{pH}$ value of 7.4 which corresponds to the $\mathrm{pH}$ value of human blood. The adsorption experiments were designed in a way that the films were first equilibrated for $45 \mathrm{~min}$ using buffer, followed by injection of the protein solutions over a period of $5 \mathrm{~min}$ and finalized by a subsequent rinsing step. At these conditions, the protein amount deposited (Fig. 7) on regenerated and washed films was determined to be $1.11 \pm 0.18$ and $0.22 \pm 0.08 \mathrm{mg} \mathrm{m}^{-2}$ for FIB and BSA, respectively (Mohan et al. 2017). The preferred adsorption behavior for FIB in contrast to BSA is observed for other surfaces as well and can be attributed to the size of FIB. FIB (340 kDa) is a larger protein than BSA $(66.5 \mathrm{kDa})$ and displays a larger contact area hereby increasing the extent of adsorption. Heat treatment of the cellulose films led to a decrease in the change of the SPR angle by the half which corresponds to lower protein adsorption $\left(0.55 \pm 0.07 \mathrm{mg} \mathrm{m}^{-2}\right.$ for FIB and $0.11 \pm 0.04 \mathrm{mg} \mathrm{m}^{-2}$ for BSA). The reduction in the adsorbed protein amount is accompanied with a change in surface morphology of the thin films since the wettability, another factor potentially playing a role, remains nearly constant after drying. A decrease in roughness minimizes the available surface area therefore leading to reduced interaction. There is not any noteworthy difference in adsorption kinetics (see sensograms, Fig. 7b) for all of the experiments, however it seems that proteins start to desorb even before the rinsing step is initiated (after $10 \mathrm{~min}$ ) at the heat treated surfaces, whereas on the washed films non-bound material is only removed upon rinsing. This could be also related to the overshooting effect as described recently (Rabe et al. 2011). Different phenomena have been described in literature to explain this effect such as the Vroman effect (competition of high affinity species with low adsorption speed vs low affinity species with high adsorption rate), and the Daly and Wertz effect (change of protein conformation after adsorption). In our case it is obvious that reorientation takes place on the surfaces since both proteins under investigation can adsorb in different conformations.

Compared to other cellulosic surfaces, for instance cellulose thin films prepared from TMSC, cellulose films made from viscose offer similar protein adsorption behavior. Depending on the adsorption parameters, e.g. adsorption time, flow rate, ionic strength and others, values in the range of $0.3-0.6 \mathrm{mg} \mathrm{BSA} \cdot \mathrm{m}^{-2}$ determined by SPR are reported in literature.
Table 2 Static contact angle for viscose thin films in different concentrations and various steps of film production

\begin{tabular}{|c|c|c|c|c|c|c|}
\hline & \multicolumn{2}{|c|}{$0.75 \mathrm{wt} \%$} & \multicolumn{2}{|c|}{$1.50 \mathrm{wt} \%$} & \multicolumn{2}{|l|}{$3.0 \mathrm{wt} \%$} \\
\hline & $\mathrm{H}_{2} \mathrm{O}$ & $\mathrm{CH}_{2} \mathrm{I}_{2}$ & $\mathrm{H}_{2} \mathrm{O}$ & $\mathrm{CH}_{2} \mathrm{I}_{2}$ & $\mathrm{H}_{2} \mathrm{O}$ & $\mathrm{CH}_{2} \mathrm{I}_{2}$ \\
\hline $\mathrm{CX}$ & n. d & $38 \pm 1$ & n. d. & $60 \pm 2$ & n. d. & $48 \pm 2$ \\
\hline Regenerated & $25 \pm 1$ & $34 \pm 1$ & $21 \pm 1$ & $36 \pm 1$ & $15 \pm 1$ & $40 \pm 2$ \\
\hline Rinsed & $34 \pm 1$ & $31 \pm 1$ & $38 \pm 1$ & $33 \pm 1$ & $27 \pm 1$ & $28 \pm 1$ \\
\hline Dried $105^{\circ} \mathrm{C}$ & $33 \pm 1$ & $34 \pm 1$ & $37 \pm 1$ & $32 \pm 1$ & $30 \pm 1$ & $32 \pm 1$ \\
\hline
\end{tabular}




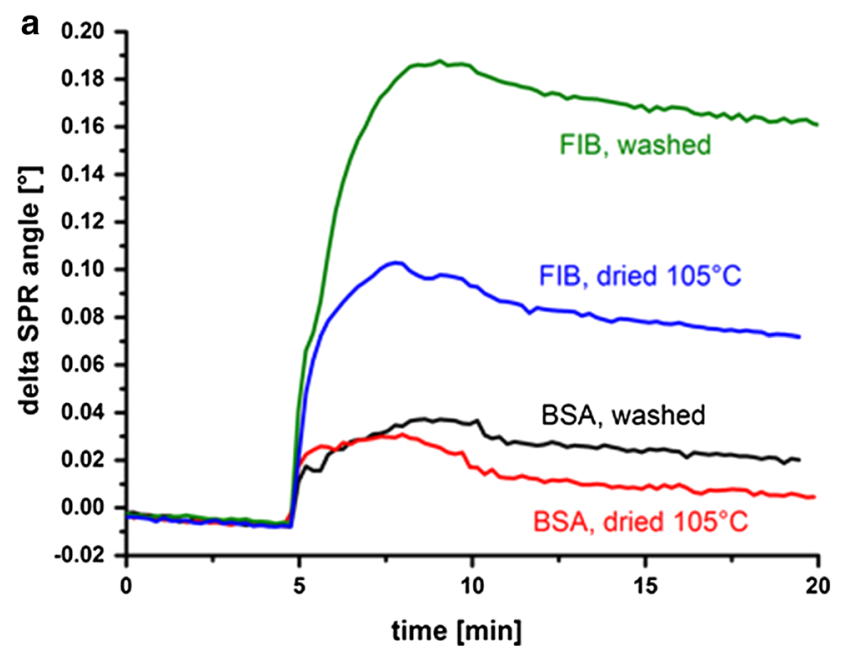

Fig. $7670 \mathrm{~nm}$ sensogram recorded during the adsorption of FIB and BSA on washed and heat treated films (a prepared from $1 \mathrm{wt} \% \mathrm{CX}$ solutions). b The amount of protein adsorbed on

\section{Conclusion}

In summary, the manufacturing and properties of cellulose thin films derived from $\mathrm{CX}$ have been presented. These films, which may be best described as two-dimensional model systems for viscose based materials, display similar properties as other cellulosic materials in terms of wettability/surface free energy and protein interaction behavior. The use of CX as starting material offers the possibility to prepare thin films in the nanometer range from aqueous solutions in large scale whereas regeneration can be performed via the gas phase. During this reaction, volatile side products are generated and $\mathrm{NaCl}$ particles are formed which are easily removed by simply rinsing the films with water. Afterwards, homogenous films are obtained which show a regular but rougher and more porous surface compared to those derived from TMSC for instance. The films show similar behavior towards proteins as other cellulose matrices. In future work, we will focus how these films perform in other areas compared to those derived from other sources such as TMSC.

Acknowledgments Open access funding provided by Graz University of Technology.

Open Access This article is distributed under the terms of the Creative Commons Attribution 4.0 International License (http:// creativecommons.org/licenses/by/4.0/), which permits unrestricted use, distribution, and reproduction in any medium,

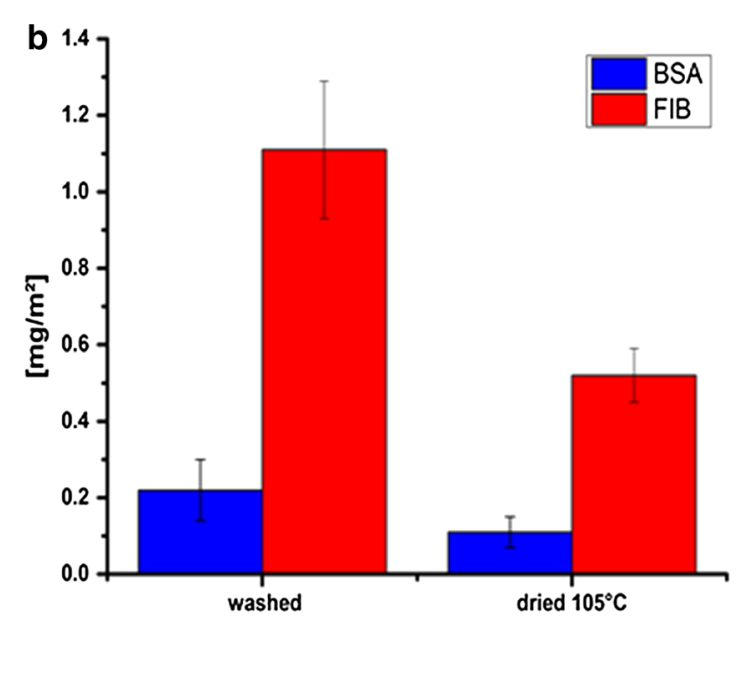

differently treated films, calculated through the change in the SPR angle via the de Feijter equation (De Feijter et al. 1978)

provided you give appropriate credit to the original author(s) and the source, provide a link to the Creative Commons license, and indicate if changes were made.

\section{References}

Andrews DA, Hurtubise FG, Krassig H (1960) The presence of monothiocarbonate substituents in cellulose xanthates. Can J Chem 38:1381-1394

Blomstedt M, Kontturi E, Vuorinen T (2007) Optimising CMC sorption in order to improve tensile stiffness of hardwood pulp sheets. Nord Pulp Paper Res J 22:336-342

Dautzenberg H, Philipp B (1970) Über Bildungsweise und Verhalten des Natriumdithiocarbonats. Z Anorg Allg Chem 375:113-123

De Feijter JA, Benjamins J, Veer FA (1978) Ellipsometry as a tool to study the adsorption behavior of synthetic and biopolymers at the air-water interface. Biopolymers 17:1759-1772

Ehmann HMA, Werzer O, Pachmajer S et al (2015) Surfacesensitive approach to interpreting supramolecular rearrangements in cellulose by synchrotron grazing incidence small-angle X-ray scattering. ACS Macro Lett 4:713-716

Filpponen I, Kontturi E, Nummelin S et al (2012) Generic method for modular surface modification of cellulosic materials in aqueous medium by sequential "click" reaction and adsorption. Biomacromolecules 13:736-742

Götze K (1951) Chemiefasern nach dem Viskoseverfahren. Springer Verlag, Heidelberg

Hämmerle FM (2011) The cellulose gap. Lenz Ber 89:12-21

Ingram G, Toms BA (1957) 868. The hydrolysis of sodium trithiocarbonate and its reaction with ethanol. J Chem Soc 4328-4344

Kaelble DH (1970) Dispersion-polar surface tension properties of organic solids. J Adhes 2:66-81 
Kargl R, Mohan T, Ribitsch V et al (2015) Cellulose thin films from ionic liquid solutions. Nord Pulp Paper Res J 30:6-13

Kontturi E, Thüne PC, Niemantsverdriet JW (2003) Cellulose model surfaces simplified preparation by spin coating and characterization by X-ray photoelectron spectroscopy, infrared spectroscopy, and atomic force microscopy. Langmuir 19:5735-5741

Kontturi E, Tammelin T, Österberg M (2006) Cellulose model films and the fundamental approach. Chem Soc Rev 35:1287-1304

Kontturi E, Suchy M, Penttila P et al (2011) Amorphous characteristics of an ultrathin cellulose film. Biomacromolecules 12:770-777

Kontturi KS, Kontturi E, Laine J (2013) Specific water uptake of thin films from nanofibrillar cellulose. J Mater Chem A 1:13655-13663

Mohan T, Spirk S, Kargl R et al (2012) Exploring the rearrangement of amorphous cellulose model thin films upon heat treatment. Soft Matter 8:9807-9815

Mohan T, Niegelhell K, Nagaraj C et al (2017) Interaction of tissue engineering substrates with serum proteins and its influence on human primary endothelial cells. Biomacromolecules 18:413-421

Niegelhell K, Süßenbacher M, Jammernegg K et al (2016) Enzymes as biodevelopers for nano- and micropatterned bicomponent biopolymer thin films. Biomacromolecules 17:3743-3749

Niinivaara E, Faustini M, Tanunelin T, Kontturi E (2015) Water vapor uptake of ultrathin films of biologically derived nanocrystals: quantitative assessment with quartz crystal microbalance and spectroscopic ellipsometry. Langmuir 31:12170-12176

Niinivaara E, Faustini M, Tammelin T, Kontturi E (2016) Mimicking the humidity response of the plant cell wall by using two-dimensional systems: the critical role of amorphous and crystalline polysaccharides. Langmuir 32: 2032-2040

Ogura K, Sobue H (1968) Studies on the derivatives of sodium cellulose xanthate. Part I. Infrared absorption spectra and characteristic frequencies of $\mathrm{C}-\mathrm{S}$ and $\mathrm{C}=\mathrm{S}$ groups in sodium cellulose xanthate and its stable derivatives. J Polym Sci Part B Polym Lett 6:63-67

Orelma H, Filpponen I, Johansson L-S et al (2011) Modification of cellulose films by adsorption of CMC and chitosan for controlled attachment of biomolecules. Biomacromolecules 12:4311-4318

Orelma H, Johansson L-S, Filpponen I et al (2012) Generic method for attaching biomolecules via avidin-biotin complexes immobilized on films of regenerated and nanofibrillar cellulose. Biomacromolecules 13:2802-2810

Owens DK, Wendt RC (1969) Estimation of the surface free energy of polymers. J Appl Polym Sci 13:1741-1747

Pallister CJ, Watson MS (2010) Haematology. Scion Publishing, Bloxham

Rabe M, Verdes D, Seeger S (2011) Understanding protein adsorption phenomena at solid surfaces. Adv Colloid Interface Sci 162:87-106

Rabel W (1971) Einige Aspekte der Benetzungstheorie und ihre Anwendung auf die Untersuchung und Veränderung der Oberflächeneigenschaften von Polymeren. Farbe Lack 77:997-1005

Reishofer D, Rath T, Ehmann HM et al (2017) Biobased cellulosic-CuInS 2 nanocomposites for optoelectronic applications. ACS Sustain Chem Eng 5:3115-3122

Schaub M, Wenz G, Wegner G et al (1993) Ultrathin films of cellulose on silicon wafers. Adv Mater 5:919-922

Široký J, Blackburn RS, Bechtold T et al (2010) Attenuated total reflectance Fourier-transform Infrared spectroscopy analysis of crystallinity changes in lyocell following continuous treatment with sodium hydroxide. Cellulose 17:103-115

Taajamaa L, Rojas OJ, Laine J et al (2013) Protein-assisted 2D assembly of gold nanoparticles on a polysaccharide surface. Chem Commun 49:1318-1320

Wolfberger A, Kargl R, Griesser T, Spirk S (2014) Photoregeneration of trimethylsilyl cellulose as a tool for microstructuring ultrathin cellulose supports. Molecules 19:16266-16273

Wolfberger A, Petritz A, Fian A et al (2015) Photolithographic patterning of cellulose: a versatile dual-tone photoresist for advanced applications. Cellulose 22:717-727 